\title{
Work environment affects patient safety climate in a government hospital
}

\author{
Dyah Utari ${ }^{1}$, Syahrul Meizar Nasri ${ }^{2}$ \\ ${ }^{1}$ Department of Public Health, Universitas Pembangunan Nasional Veteran Jakarta, Indonesia \\ ${ }^{2}$ Department of Occupational Health and Safety, University of Indonesia, Indonesia
}

\begin{tabular}{l} 
Article Info \\
\hline Article history: \\
Received Aug 24, 2020 \\
Revised Nov 18, 2020 \\
Accepted Jan 3, 2021 \\
\hline
\end{tabular}

Keywords:

Patients

Safety climate

Work environment

Workers

\begin{abstract}
The work environment becomes one of the motivations for someone to work. The climate of working environment is very important for a person, especially for medical staffs who actually handle and deal with sick people. Medical officers are required to always be friendly, agile, discipline and polite in front of patients thus the patient feels comfortable and quiet. This study aimed to analysis the relationship between work environment and patients' safety climate. This study was conducted with questionnaires. Based on the survey results, it was revealed that the hospital environment determines the form of services provided to patients. The working environment has positive relationship to patients' safety climate. At the hospital, there are latent conditions that may be a risk of accidents that come from heavy work load, management and inadequate supervision, work environment filled with pressure and inadequate communication systems. Work environment contributes greatly because the overall work in providing services to patients requires good teamwork.
\end{abstract}

This is an open access article under the CC BY-SA license.

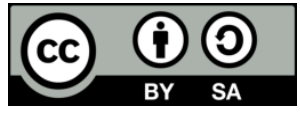

\section{Corresponding Author:}

Dyah Utari

Department of Public Health

Universitas Pembangunan Nasional Veteran Jakarta

Jl. R.S Fatmawati No. 1, Jakarta Selatan 12450

Email: dyahutari@upnvj.ac.id

\section{INTRODUCTION}

Patient safety is now being recognized as a large and growing global public health challenge [1]. Therefore, the Ministry of Health in Indonesia has set out eight factors to support patient safety, those are external factors of hospitals, organisational factors and management, working environment, personnel, teamwork, workload, patient factors itself and communications [2]. Broadly speaking, these eight points are grouped into three main components: i) technical, including equipment and supplies [3], ii) the organisation, including policies, procedures, protocols and managerial, and iii) the human resource factor [4]. All components have to be comprehensively well in order to avoid mistake and to provide services to the community.

To provide public health services, the organizers must ensure the psychological state of their security officers. This is an important part because the officers of health providers (nurses and doctors) are the forefront of the public service [5]. To guarantee the psychological state, generally errors occur in health care workers is $44 \%$ caused by technical errors by the lack of skills, $17 \%$ by misdiagnosis and $12 \%$ is due to failure to prevent accidents [6].

The concept of patient safety must be understood and implemented by every ranks of the management of health services from the highest level to the lowest level. Thus, health care can be 
implemented properly and filled with a sense of protection to patients [7]. The basic concept of patient safety has been proposed since centuries ago by Hippocrates which was then used by the doctors in the medical profession oath. This concept states that "primum non nocere" which means the first and foremost principle is to do the job without harm to or endanger patients themselves [5]. One of the things that plays a role in encouraging and motivating behavioural health care is individual psychology and principles held by the community [8]. Hence, the role of the working environment in health service delivery to the community is very influential.

The working environment discussed in this research is not intended to lead to the physical environment, but rather the working climate in the unit and the hospital. Lake [9] defined the work environment as a set of characteristics that support or hinder the performance. According to Gershon [10] safety climate and safe working environment are a continuity of mutual influence as explained by the following cycle as shown in Figure 1 [10].

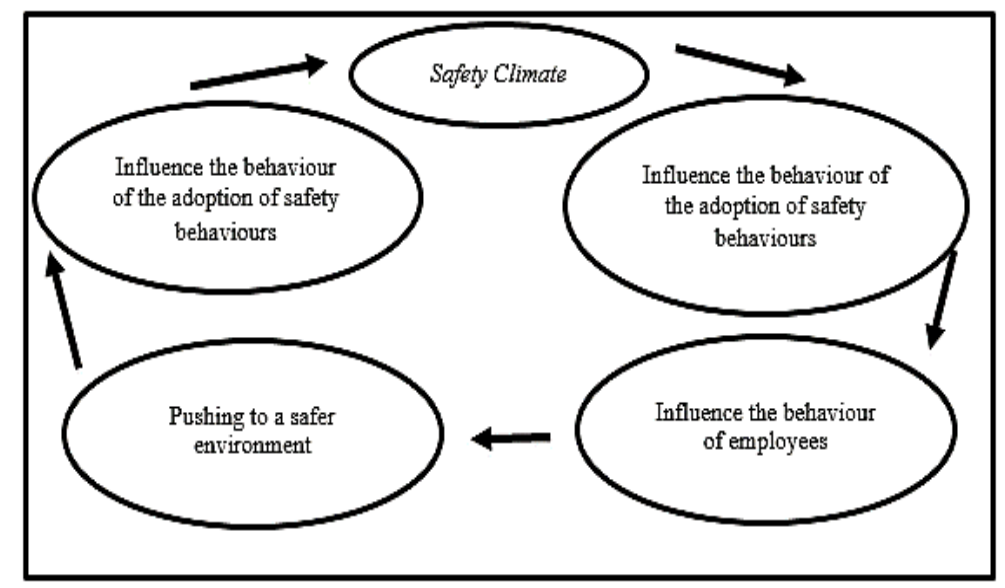

Figure 1. Relationship between safety climate and safer working environment

The technical error is closely associated to the working environment for hospital personnel. This happens because basically every process of service delivery is about the communication between the hospital staffs (doctors/nurses). Hence, communication and teamwork are things that must be prioritised in the provision of services to the community.

The X Hospital is a government hospital that does not yet have an official patient safety organizational structure. The patient safety program is only a small part and is attached to other divisions. This becomes a big problem because the absence of a specific organization for patient safety shows a weak management commitment. Communication and teamwork cannot be optimal because employee perceptions of patient safety are very low. The purpose of this study was to determine the relationship between the work environment and the patient safety climate. With the knowledge of this relationship, it is hoped that it can become an evaluation for employees and also management regarding the patient safety climate conditions at X Hospital.

Urgent for X Hospital to immediately form a special organization related to patient safety. Commitment from the leadership and management is required in order to run a patient safety program. This commitment can be realized in the form of a micro policy for the hospital, making/improving SOPs in all aspects so that it leads to the achievement of patient safety goals. Socialization and training for all employees so that they can increase knowledge related to patient safety and ultimately a patient safety climate for all aspects of service at X Hospital.

Effective communication is the key to create a positive climate patient safety in hospitals. Effective communication types are required in a positive patient safety familiarization [11]. Effective communication supports comfortable working environment for all elements. According to Idris et al. [12] communication becomes an important part in the community for physical and psychological interaction. In order to make effective communication in X Hospital, management and all elements must have the same goals and perceptions regarding patient safety. Programs and activities that can be carried out are routine meetings, sharing sessions as well as joint monitoring and evaluation. The involvement of employees in the program

Int. J. Public Health Sci. Vol. 10, No. 1, March 2021: $61-67$ 
will reduce the gap between leaders and employees so that communication is easier to form and run effectively

Communication (verbal and non-verbal) is essential for patient safety. Communication is often the cause and source of the threats prevention to the patient. Often workplace accidents are caused by failure to communicate effectively between elements in the work place [13]. This communication can be controlled by a senior leadership, hence their role is to know and understand the interaction patterns between subordinate and the patient. By performing these functions, every communication that exists within the institution/ organisation of health services can be ascertained effectively and does not impact to physical and mental state of the patients [14]. There are two kinds of communication that occur within the hospital in terms of perpetrators, those are internal communications and external communications. Internal communication is the communication that occurs within and for the benefit of the organisation, traits that are visible to the organisational structure [15] Communication between team members and team leader is an example of internal communication because both parties are in one organisation.

External communication is the communication that happen between the organisation and the elements outside the organisation. The relationship between the hospital staffs and patients is one of the types of external communication. Internal communications and external communications have an equally important role in patient safety. Pronovost stated that most medical errors occur in the communication gap between team members [16]. The failure of providers to cooperate or communicate as a team is one of the factors that contribute to medical errors or other patient safety incidents [17].

The difference between a hospital or health care provider industry and other fields is that selfservice for consumers is impossible. For example, a doctor, no matter how expert they are and their level of understanding, cannot cure a patient without the help of nurses, pharmacists, radiographers or even janitor to ensure that these patients are in a clean environment that is not infected by other diseases. It can be concluded that the provided health services are in a form of community participation between the management bodies [18]. Researchers agreed that solid teamwork is required to carry out their duties properly and provide health assistance to patients.

Good cooperation is needed for all elements of the hospital to work together as a solid team. This collaboration will result in a holistic care for patients. Similarly, in the areas of safety, patient safety will not be likely to be realised if there is no cooperation between the team members of existing service providers. Therefore, cooperation should be promoted to the team among the leaders and staff who deal with the public directly. If everything works well and everyone is connected to each other as they should be, the best service quality can be provided [19].

Teamwork is the process of working in groups with participation from the leader, divided responsibility, share of interest, intensive communication, focus on the future, focus on the task, creative talent and responds quickly to achieve organisational goals [20]. Effective team leaders encourage the team to perform better. Leaders must be able to manage differences in ability, talent and expertise of the team members in order to achieve the goals that have been set. The X Hospital needs to increase teamwork in providing health services that prioritize patient safety. This teamwork can be strengthened by holding workshops, character building and routine discussions involving all elements.

In most health care organisations, collaborative team approach will make a cultural change in the way the organisation works [21]. Patient safety needs effort from the whole team, the team most effectively has the same purpose in the work, and their work ineffective teams have the same goal in work and their work ineffective teams created opportunities for error/error [22].

\section{RESEARCH METHOD}

This research is classified as an observational study. The approach used in this research is crosssectional study to understand the dynamics of the correlation between independent and dependent variables through observation and data collection concurrently. In this study, analytical survey will be conducted to understand the employees' perceptions of the working environment regarding patient safety climate. The research samples were employees of X Hospital medical providers, support services, and support services. Total number of sample is 71 people, which has qualified the minimum survey sample of 30 people [23].

A questionnaire was used to determine the independent variables. The questionnaire was compiled based on discussions with some of the leadership and management team members of the hospital regarding the factors that are expected to affect patient safety climate in the X Hospital. The questionnaire was developed to describe how the variables become indicators to formulate questions. The questionnaire was then adjusted to Patient Safety Climate on Health Care Organisation to measure the dependent variable, hence the continuity between the two is ensured. 
Prior to commencing the work, the questionnaire was tested beforehand to measure the validity and reliability of the instrument. Validity test is to ensure that the measuring instrument is indeed appropriate. Reliability test aims to perceive the consistency of the instrument. The test instrument was conducted using Cronbach's alpha. Based on the results of the reliability test, the Cronbach alpha value was 0.741 , so it can be concluded that the questionnaire used is reliable. The validity level of the questionnaire in this study was measured by correlating between item scores questions and a total score constructs or variables. Meanwhile, the correlation technique was used to test the validity of the scale is the product moment correlation. Measuring the validity level of the measure in this study was carried out by correlating the item score of the question with the construct or variable total score. The results of the validity analysis on the perceived scale of factors that affect the patient safety climate show that of a total of 35 question items, all of them are valid.

Data managements conducted in this study were questionnaires, the questionnaire collection, coding, data input, and data analysis. Analysis of the data is a continuation of data processing stages. Data analysis is the process of simplification of data into a form that is easier to read and interpret. Work environment predicted from sub variable communication and team work. In this study, data analysis includes analysis of univariate, and bivariate analysis using chi square test.

\section{RESULTS AND DISCUSSION}

\subsection{Result}

Distribution of respondents' perceptions of the work environment variables were divided into two categories: good and less good. Work environment variables were translated into two sub variables, those are communication, and teamwork. The variable analysis calculation of the work environment is the sum of the two sub variables above as shown in Table 1.

Tabel 1. Respondents' perception regarding work environment, sub variable communication, and sub

\begin{tabular}{ccc}
\multicolumn{3}{c}{ variable team work } \\
\hline Variabel and sub variabel & Amount & Percentage (\%) \\
\hline Work evironment & & \\
Good & 40 & 56.3 \\
Less & 31 & 43.7 \\
Communication & & \\
Good & 52 & 73.2 \\
Less & 19 & 26.8 \\
Team work & & \\
Support & 53 & 74.6 \\
Does not support & 18 & 25.4 \\
\hline
\end{tabular}

In the work environment system variables, the results were categorised based on the cut-off point values mean which showed that $40(56.3 \%)$ of respondents stated a good working environment. Approximately 31 (43.7\%) of respondents stated that the work environment is less than good. However, when it is seen from the relationship of each sub variable of work environment variables, the dependent variable is as follows:

1) In the communication variables, the results were categorised according to the cut-off point of the mean value, which is then divided by the communication that occurs either or less good. In the table above, 52 (73.2\%) of respondents stated that the existing communication is good, while 19 respondents stated that the communication was lacking.

2) In teamwork variable, the results were categorised based on the cut-off point of mean values, which showed that 53 respondents $(74.6 \%)$ stated that the teamwork is good. While 18 respondents $(25.4 \%)$ stated that there is a lack in team collaboration.

The statistically significant bivariate analysis of work environment (which consists of communication and teamwork) showed $\mathrm{p}=0.046$. The value is smaller than $\alpha(0.05)$, thus it can be concluded that work environment factors have no significant relationship to patient safety in X Hospital . The proof of hypothesis for the above results are: H0: there is no relationship between the working environment and patient safety climate $\mathrm{H} 1$ : there is a relationship between the working environment and patient safety climate. Results p-values 0.046 with $\alpha$ of 0.05 , means $\mathrm{H} 0$ is rejected and $\mathrm{H} 1$ is accepted. The results of the bivariate analysis using chi square analysis above are summarised as shown in Table 2. 
Table 2. Chi square analysis

\begin{tabular}{ccccc}
\hline \multirow{2}{*}{ Work environment } & \multicolumn{2}{c}{ Patient safety climate } & \multirow{2}{*}{ Total } & \multirow{2}{*}{ pood } \\
\cline { 2 - 5 } & Less & $18(25.4 \%)$ & $40(56.3 \%)$ & 0.046 \\
Good & $22(31.0 \%)$ & $17(23.9 \%)$ & $31(43.7 \%)$ & \\
Tess & $14(19.7 \%)$ & $71(100 \%)$ & \\
\hline
\end{tabular}

\subsection{Discussion}

The working environment in the hospital consists of physical and non-physical environment. The definition of the non-physical environment in this study is a work climate where employees interact to perform daily tasks. The working environment consists of communication and teamwork. The working environment in the hospital determines the form of services provided to patients [24]. This demonstrates that the working environment becomes a very important part and determines the patterns of interaction that will be developed and implemented to the public (consumers).

The results of this study indicated that the working environment has positive relation to patient safety climate. At the hospital, there are latent conditions that may be a risk of accidents, such as too heavy work load, inadequate supervision and management, high pressure in work environment and inadequate communication systems. Work environment contributed greatly because the overall work to provide services to patients requires good teamwork. This is in accordance with the study by Zwetsloot et al. [25] which stated that trust and fairness in the workplace relate directly to the consumer. In this case, it was started on teamwork and implemented in communication vertically and horizontally at the agency. Teamwork is a picture of the whole organisation. To do the work, teamwork is needed to accomplish the goal. In the organisation of service providers such as hospitals, almost all of the work is the result of teamwork, whose members consist of different disciplines.

To create a good teamwork, facilities are required and also the opportunity for team members to actualise themselves in terms of patient safety. Additionally, the opportunity will increase the functionality and also improve team collaboration, adding positive perception to employees regarding patient safety. The positive perception of individuals is expected to increase patient safety climate at a higher level, namely the level of daily teamwork and then the level of the organisation. Thus, the teamwork between manager and staffs should be started from a transparent and effective communication [26]. Understanding both perceptions within the organisation is important for every individual in it. Thus, it will be implemented by health care personnel when they deal directly to the patients.

Gershon et al. [10] connected the dimensions of safety climate with safe work practices in the workplace with the support of the management of the programs of safety. The absence of barriers between work and safe work practices, clarity and command line of employment and conflicts are minimal. Moreover, communication between staffs, frequent feedback on safety supervisor and the availability of protection and control are improved. The results of this study also showed similar results, in which patient safety climate is significantly influenced by the working environment.

The next sub variable to assess the work environment is communication. Communication within the team can be done vertically or horizontally. Vertical communication leads to communication built between the leader and team members. This communication can be a direct communication through verbal communication in order to coordinate and communicate indirectly through regulation and medical records of the patient's progress. Communication pattern described above differs with the type of work in other places, such as the fields of industry, manufacturing, construction and other technical fields. Provision of services in the hospital cannot be undertaken by just one section or profession, for example, to care for patients with fractures.

The services provided must be comprehensive, starting from patient registration, emergency care, supporting tests, pharmaceuticals, to hospitalisation or even surgery. The time required is more than just a few minutes. The treatment for these patients requires absolute teamwork and effective communication. A communication error can be fatal for the patient, especially on shift change. Communication is also influenced by the position of a person in the team.

It can be concluded that good communication will form an ideal team for optimum work environment to implement patient safety. This result is supported by the theory proposed by Nelson [27] which mentioned that the hierarchy of a hospital affects communication patterns. The study showed that the leadership in the hospital microsystem (indoor/section) creates small communication barriers between the head of the management and employees who are on the front line/service providers. Nurses and other employees should be given the right to express their opinions and to propose an idea of patient safety [28].

The optimum working environment gives positive perception to employees regarding the overall patient safety. It is similar to the theory which stated that individuals gain perception based on the work 
environment to help interpret the events, establish the minimum expectations of behaviour and understand the expected behaviour and its consequences [29].

The behaviour of each individual affects the team's performance and vice versa. According to Gershon [10], safety climate and safe working environment are a continuity of mutual influence. A safe working environment will support and influence the safe behaviour of the individual. If the individual implements safe behaviour, then the individual is expected to become an example for other workers.

In general, the results of research on work environment is similar to the results of research by Currie [30] which stated that the patient safety climate is positively influenced by three dimensions: i) A supportive environment as the perception of the social environment at work and the support derived from the environment, ii) involvement with safety as the focus for all and everyone involved in patient safety, and, iii) communication as the perception of the shape and accuracy of communication regarding safety in the organisation. In most health care organisations, collaborative team approach will make a change in how the organisation's culture is developed. Patient safety needs team effort, the most effective teams have the same goal in their work, their work ineffective teams have the same goal in their work and their work ineffective teams created opportunities for error/error [31].

\section{CONCLUSION}

The statistically significant bivariate analysis of work environment (which consists of communication and teamwork) showed $\mathrm{p}=0.046$. The value is smaller than $\alpha(0.05)$, thus it can be concluded that work environment factors have no significant relationship to patient safety in X Hospital. The proof of hypothesis for the above results are: H0: there is no relationship between the working environment and patient safety climate $\mathrm{H} 1$ : there is a relationship between the working environment and patient safety climate. Results p-values 0.046 with $\alpha$ of 0.05 , means $\mathrm{H} 0$ is rejected and $\mathrm{H} 1$ is accepted. Thus, it is concluded that there is a relationship between the working environment and patient safety climate. It means that work environment played crucial roles in managing patinet safety climate.

\section{REFERENCES}

[1] World Health Organization, "Patient safety Global Action on Patient Safety," World Health Organization Excecutive Boards, 2018.

[2] Depkes RI., "National Hospital Patient Safety Guidelines (Patient Safety)/Pedoman Nasional Keselamatan Pasien Rumah Sakit (Patient Safety)," Jakarta: Depkes RI. 2008.

[3] Djati, Rr. A. P., Cahayanti, S. R., Chairani, E., Koestoer, R H., and Hartono, D M., "When LCA Applies To Health Service Industry," Journal of Environmental Science and Sustainable Development, vol. 1, no. 1, pp. 40-62, 2018, doi: https://doi.org/10.7454/jessd.v1i1.12.

[4] Van der Schaaf, T. W., "Near Miss Reporting in the Chemical Process Industry," PhDT, 1992

[5] McLinton, S.S., Dollard, M.F., and Tuckey, M.M.R, "New perspectives on psychosocial safety climate in healthcare: A mixed methods approach," Safety Science, vol. 109, pp. 236-245, 2018

[6] Taveras, M.P., "Access to health care and Patient safety: A model for measurement and analysis," University of Miami, 2011.

[7] Potter, R.E., Dollard, M.F., Owen, M.S., O’Keeffe, V., Bailey, T., Leka, S., "Assessing a national work health and safety policy intervention using the psychosocial safety climate framework," Safety Science, vol. 100, pp. 91-102. 2017.

[8] Mc Ternan, W.P., Dollard, M.F., La Montagne, A.D, "Depression in the workplace: An economic cost analysis of depression-related prod uctivity loss attributable to job strain and bullying," Work Stress, vol. 27, no. 4, pp. 321338, 2013.

[9] Lake, E. T., "Development of the Practice Environment Scale of the Nursing Work Index," Research in Nursing \& Health, vol. 25, no. 3, pp. 176-188, 2002.

[10] Gershon, R.R.M., Karkashian, C.D., Grosch, J.W., Murphy, L.R., Cejudo, A.E., Falanagan, P.A., Bernacki, E.,Katsing, C., dan Martin, L., "Hospital safety Climate and its realtionship with safe work practices and workplace exposue incidents," Journal of Association for Professionals in Infection Control and Epidemiology Inc, vol. 28, no. 3, pp. 211-221, 2000.

[11] Merrill, K.C., "The relationship among nurse manager leadership style, span of control, staff nurse practice environment, safety Climate, and nurse-sensitive patient outcomes," PhD Thesis. College of Nursing, University of Utah, 2011.

[12] Idris, M.A., Dollard, M.F., Coward, J., Dormann, C., "Psychosocial safety climate: conceptual distinctiveness and effect on job demands and worker psychological health," Safety Science, vol. 50, no. 1, pp. 19-28, 2011.

[13] Byers JF, White SV., "Patient safety: Principles and practice," Springer Publishing Company, 2004.

[14] Gallagher, R., "Compassion fatigue," Canadian Family Physician, vol. 59, no. 3, pp. 265-268, 2013.

[15] Miftha Thoha, "Leadership in Management/Kepemimpinan Dalam Manajemen," PT. Raja Grafindo Perkasa, Jakarta, 2004. 
[16] Pronovost, P.J., et al, "Evaluation of the culture of safety: Survey of clinician and managers in an academic medical center," Journal of Quality Safety Health Care, vol. 12, no. 6, pp. 405-410, 2003.

[17] Blendon, R., Desroches, C., Brodie, M., Benson, J., Rosen, A., Scheider, E., Altman, D., Zapert, K., Herrmann, M. and Steffenson, A, "Patient safety: views of practicing physicians and the public on medical errors," New England Journal of Medicine, vol. 347, pp. 1933-40, 2002.

[18] O'Keeffe, V., Thomson, K., Tuckey, M.R., Blewitt, V., "Putting safety in the frame: Nurses' sensemaking at work," Global Qualitative Nursing Research, 2015.

[19] American Nurses Association Health Risk Appraisal Executive Summary, 2017. [Online]. Avaible: http://www.nursingworld.org/MainMenuCategories/WorkplaceSafety/Healthy-Nurse/HRA-ExecutiveSummary/ANA-HRA-Executive-Summary.pdf.

[20] Buchholz, Steve, "Creating the High Performance Team," Canada: John Wiley \& Sons, Inc, 2000.

[21] Rozovsky, F.A., Woods, Jr, "The Handbook of Patient safety Compliance, a Practical Guide for Health Care Organization," USA: Jossey-Bass, 2005.

[22] White D, Plews-Ogan ML, Nadkarni MM, Forren S, Leon D, Marineau D, Schorling JB, Schectman JM, "Patient safety in the ambulatory setting, A clinician-based approach," Journal General Internernal Medicine, 2004.

[23] Gay, L.R., dan P.L. Diehl., "Research Methods for Business and Management," New York; Mac Millan Publishing Company, 1992.

[24] Dollard, M.F., Opie, T., Lenthall, S., Wakerman, J., Knight, S., Dunn, S., McLeod, M, "Psychosocial safety climate as an antecedent to work characteristics and psychological strain: A multilevel model," Work Stress, vol. 26, no. 4, pp. 385-404, 2012.

[25] Zwetsloot, G.I.J.M., van Scheppingen, A.R., Bos, E.H., Dijkman, A., Starren, A, "The core values that support health, safety and well-being at work," Saf. Health At Work, vol. 4, no. 4, pp. 187-196, 2013.

[26] Hoffmeister, K., Gibbons, A.M., Johnson, S.K., Cigularov, K.P., Chen, P.Y. and Rosecrance, J.C, "The differential effects of transformational leadership facets on employee safety," Safety Science, vol. 62, pp. 68-78, 2014.

[27] Nelson, Shanelle, et al., "Patient safety climate: Variation in Perception by Infection Preventionists and Quality Directors," Interdisciplinary Perspectives on Infectious Diseases, 2011.

[28] McClure, M.L. and Hinshaw, A.S, "Magnet hospitals revisited," Washington, DC: American Nurses Publishing, 2002.

[29] Naveh, E., Katz-Navon, T. and Stern, Z, "Treatment errors in healthcare: A safety Climate approach,” Management Science, vol. 51, no. 6, pp. 948-960, 2011.

[30] Currie, dan Lynne, "Assessing safety Climate supports targeted quality improvement interventions," Paper Presented at NICE CConference, 2007.

[31] Nuraini, T., Novieastari, E. and Yetti, K., "Evaluation of nursing care behavior culture program's implementation at Dharmais Cancer Hospital," ASEAN Journal of Community Engagement, vol. 3, no. 1, pp. 51-71, 2019, doi: https://doi.org/10.7454/ajce.v3i1.140. 